\title{
E-Textbook Technologies for Academics in Medical Education
}

\author{
Anna Ren-Kurc ${ }^{1}$, Magdalena Roszak ${ }^{2}$, Iwona Mokwa-Tarnowska ${ }^{3}$, \\ Mirosława Kołowska-Gawiejnowicz ${ }^{1}$, Jan $\mathbf{Z y c h}^{4}$, Wojciech Kowalewski ${ }^{5}$ \\ ${ }^{1}$ Faculty of Mathematics and Computer Science, Adam Mickiewicz University in Poznan, \\ Poland \\ 2 Department of Computer Science and Statistics, Poznan University of Medical Sciences, \\ Poland \\ 3 Language Centre, Gdańsk University of Technology, Poland \\ 4 Faculty of Social Science, Jan Kochanowski University in Kielce, Poland \\ ${ }^{5}$ Faculty of Geographical and Geological Science, Adam Mickiewicz University in Poznan, \\ Poland
}

\begin{abstract}
Public universities in Poland receive fairly limited financial support for creating e-textbooks (interactive online textbooks) and lack the appropriate ICT competences among teaching staff, especially in the case of non-technical universities. The authors propose a pedagogical and technological paradigm for e-textbooks in medical education using open source software with minimal IT skills required. Technologies used to develop e-textbooks are connected with: publication and distribution of e-textbooks, e-book readers, and editing tools. The paper also discusses a survey that targeted students of medical sciences, which focused on their understanding of their educational needs that can be met through new online resources as well as their expectations of how such e-textbooks should be like.
\end{abstract}

\section{Introduction}

New educational approaches in the academia have emerged, leveraging technology such as e-textbook systems (Blaž et al., 2012; Jump, 2011). Students are well aware of them and expect teachers to use them and universities to be prepared with adequate IT infrastructure (Kirkwood \& Price, 2014; Walker et al., 2012). As paper textbooks are not sufficient, e-learning systems managing e-textbooks and other educational materials (atlases, films, recordings of experiments) are being implemented nowadays (Szulc, 2018). Additionally, students have a wide range of software to connect to these systems with their electronic equipment. This is already hap- 
pening at many universities, in Europe and elsewhere. However, authors do not observe interest in creating e-textbooks (interactive online textbooks) in Poland (Dutkiewicz et al., 2018). The key reason are limited financial support and lack of competences among ICT teaching staff, especially at nontechnical universities (Roszak \& Kołodziejczak, 2017; Roszak et al., 2019).

Public universities in Poland have quite limited financial resources for the implementation of educational projects that aim to create interactive online resources. In addition, IT departments employ a limited number of employees who can help in the implementation of online projects. For this reason, authors suggest using open source software, easy to use for staff with minimal IT skills. This approach is supported by research findings presented in this paper. According to specialists in information technology, including in multimedia technology, an increase in the knowledge and IT competencies of staff in the field of online production tools should be addressed urgently, while implementing open source software to facilitate preparation and better management seems to be a reasonable compromise (Kołodziejczak et al., 2015; Ren-Kurc et al., 2013).

In order to be able to create e-textbooks (interactive online textbooks), in addition to the relevant ICT skillset, IT knowledge and pedagogical competences are necessary to help realize a project tailored to the needs of recipients of content and universities (Blaž et al., 2012; Ren-Kurc et al., 2013). Hence, research in these two areas is necessary to make correct and effective implementations, which will have an impact on the quality of the academic education process. Thus, creating e-textbooks is a task performed as part of multidisciplinary projects.

Research conducted by the authors in the academic year 2017/2018 aimed to analyse how higher education medical institutions are prepared to support their curricula with interactive online textbooks, and help to prepare their staff to develop web-based resources that would contain visualisations with embedded interactivity. The authors propose a pedagogical and technological paradigm for such materials, called e-textbooks, which in their opinions must be structured around student-centred pedagogy and should be developed using applications for creating e-books, which makes it possible to develop a new e-publication and modify the one already existing. The paper also discusses the survey that targeted students of medical sciences. It focused on their understanding of their educational needs that can be met through new online resources and their expectations of what such materials should be like.

The paper resulted from research conducted by the members of Poznan Association of Academic E-learning local group in the academic year 
2017/2018. The local group meets at the Medical E-education Lab of the Department of Pathophysiology, Poznan University of Medical Sciences. Its members started collaborating in December 2015.

\section{The Pedagogical Paradigm Behind Interactive Online Textbooks}

There are different pedagogical paradigms that can have an impact on the development of interactive online materials. The behaviourist understanding of learner actions expressed in Bloom's Taxonomy is visible in the way course developers prepare tasks and phrase aims and objectives (Anderson \& Krathwohl, 2001; Heriot-Watt University, 1999). The cognitive approach to communication between people, based on intersubjective, culturally grounded experience and conscious exploration, leading to a substantial increase in competence, underpins much of what students and teachers do in class (Holme, 2009; Lakoff, 1987). The constructivist environment in its variety encourages the development of critical, self-reflective and analytical skills through various types of interactions (Burke, 2003; MokwaTarnowska 2013). All the major paradigms have influenced learning design to foster best practices in online education. However, it is constructivism that provides the best theoretical framework to design interactive online textbooks as it stimulates learners to pursue new ways of increasing subject matter awareness.

The constructivist environment provides various opportunities, methods, and tools to build conceptual systems. Students can use technologies pervasive in their lives such as personal computers, tablets, or smartphones to access educational materials. They can gather information through reading uploaded texts and listening to podcasts and webcasts, which may result in them being able to construct new mental models. They can develop a deeper understanding due to a variety of inquiry-based and problemsolving activities embedded in their online textbooks. They are also able to actively participate in the learning process by interacting with preprepared tasks and purpose-designed resources, and by negotiating meaning through communication with tutors, as well as collaboration with other group members. Materials designed according to constructivist principles include authentic materials and complex resources, not simplified texts that are specially adapted to meet the course aims and objectives. The inclusion of critical thinking and problem-solving activities based on real life situations makes students interested in learning and eager to get more engaged. 
A constructivist classroom helps students improve different soft competencies such as collaborative, self-reflective, analytical and critical thinking skills. If it is equipped with specially designed online materials, it can provide more versatile interactions with resources and activities, peers and tutors than traditional sessions. Resources together with activities included in interactive textbooks create an educational programme that involves indirect communication with the tutor, who supports their students by providing them with pre-emptive feedback. Correct answers to quiz questions, comments and advice stored in the system help them understand the subject matter. Analyses of theoretical writings and good practice examples, due to their easy-to-update nature, familiarize them with prevailing and opposing views, new facts, fresh evidence, and plausible and reasonable interpretations. Even introvert students are more encouraged to actively participate in creating knowledge and in accommodating novel concepts within their existing conceptual systems because they can engage in other types of interactions than those available in a traditional, paper-based setting (MokwaTarnowska, 2013).

Introducing interactive online textbooks with non-linear paths and a variety of tasks into academic course curricula is an important step to creating an effective learning environment. An online textbook should contain short and long activities which keep students focused, and which help them meet course aims and objectives. Well-designed interactive learning materials with video and audio, infographics, and various activities embedded in the running text may substantially increase their engagement, making it easier for them to understand new concepts and complex issues.

Online resources that consist of reading passages that are several pages long may be difficult to learn from. Thus, it is advisable to supplement them with activities such as self-assessment questions or reflection points or reflection tasks, with answers, suggestions, advice and guidance (Heriot-Watt University, 1999; Mokwa-Tarnowska, 2017). Research on the average attention span has shown that students can concentrate on learning and reading for as little as twenty minutes (Briggs, 2014; Smith, 2013). Therefore, if intensive learning by reading is broken up by activities, student concentration increases. This means that after a break necessary to perform a task, students can focus on new ideas better, and thus faster develop their skills and knowledge. It must be remembered that the best ratio is when an online text has one activity per page. If there are too many tasks incorporated into the resource, they cause too much disturbance, and as a result they dissuade learners from reading the basic text, as well as from learning altogether. Activities that break up resources must be carefully thought out, because if 
students find any of them boring or in any way unsatisfactory, inadequate or badly formed, they will skip most of them or even all of them, treating doing them as a waste of time.

Students working in an online environment and using e-textbooks built around constructivist principles acquire a deeper understanding of the educational processes itself. They better understand the nature of the difficulties they encounter and find solutions more easily, which shows them how to overcome problems. They develop awareness, which helps them in the process of continuous improvement.

\section{Technologies Used to Develop E-textbooks}

Publication and Distribution of E-textbooks. E-textbook, as every library item or scientific publication, requires:

- substantive reviewing and proper design of graphic, multimedia and interactive elements,

- proper technical editing of these elements,

- distribution among students.

The method of publication of an academic e-textbook is closely related to the technology of editing it. This decision is typically made with help of the IT department of a university or a publishing house (Blaž et al., 2012). The help is applied to the publication (the text itself, graphics, multimedia, references to interactive elements of the e-textbook) and the format (HTML5, ePUB, Javascript). Selected basic challenges related to the publication of academic e-textbooks are described below.

Commercial distribution. Commercial publishing houses publish etextbooks in all formats that can be used to present the contained multimedia and interactive elements. Publications are available in online bookstores, free of charge in some cases (e.g. virtualo.pl). A student buying such an e-textbook distributed in this manner, usually in a single-file format (e.g. ePUB, mobi, pdf), needs to take into account that multimedia and interactive elements will be available from multimedia servers on the Internet (e.g. YouTube, Vimeo). Publishing houses offer authors saving their e-textbooks in a format that allows correct publication. Although it is a paid service, authors have a guarantee of the correctness of this process.

University libraries. Universities often make use of offers from commercial publishing houses and buy e-textbooks. In this case, the e-textbooks are made available for the duration of the sales contract only from the com- 
puters in the library's reading room, often on a limited number of stations. With the large number of students and limited number of posts, access to e-textbooks becomes very limited. The situation is similar to sharing paper textbooks in a reading room.

Internet rentals. Commercial publishing houses often offer the service of paid e-textbooks rental. An e-textbook reader application works on publishing house servers, which a student launches (after paying the fees) using a web browser. Internet access is required for the duration of work with the e-textbook. Partial publishing on web services is not a newly introduced limitation in the rental mode. A low rental price makes this offer attractive.

Non-commercial distribution. Authors often find external financing sources for the editing of e-textbooks, multimedia and interactive elements (e.g. MNiSW grants, EU grants). The e-textbook whose creation was financed from public funds is often accompanied by the requirement of public accessibility. In this case, the e-textbook is published as freely available in publishing houses, or on servers and under the supervision of the IT department of the university that prepared it.

Private foundations also launch and pay for IT infrastructure in order to publish e-textbooks available at no charge. For example, over 2000 etextbooks from many academic fields can be found at openstax.org.

Readers. An e-textbook should allow the reader to actively support mental and memory processes and include multimedia and interactive elements. Such elements are always unprintable and require information processing by the electronic device on which the application for reading the e-textbook is run. Reading is mainly performed in one of the following two modes:

1. The reader application works on the server together with e-textbooks. E-textbook publishers often finance the creation of such an application by programmers and install it on their servers. The reader most often connects with this kind of application via a web browser. Access to the Internet is required throughout the course of working with the etextbook.

2. The reader application works on the student's device. E-textbook is published on the Internet, often with free access (no registration, fees, etc.). The reader does not have to have uninterrupted access to the network - the e-manual can be copied to the student's device. Nevertheless, it must be remembered that multimedia and interactive elements are most often served on demand and stored on multimedia Internet servers 
(e.g. YouTube, TeachersTube, Vimeo) or web servers with technologies enabling launching applications that implement interactivity (e.g. tests with result checking, process simulations, animations controlled by the reader).

It is worth paying attention to the following two very closely related concepts. Passively interactive element: passively reacting to the user's action (in computer science on the generated event). Actively interactive element: processes information (several events, time) generated by the user and reacts on that basis. Dynamically generates reaction, in a manner similar to games.

A test informs the student on the correctness of the answer given after each question is only a passively interactive element of an e-textbook. The test that provides a summary result and the comment on the result at the end is an actively interactive element. All types of interactions with the e-textbook usually work on Internet servers due to the need to process information, which is not always possible on the student's device. This means that Internet access is needed to run them.

The student's device is usually a high-quality smartphone, tablet, laptop, or desktop computer. The technical parameters that differentiate them (memory size, processor speed and class, screen resolution, etc.) sometimes cause inability to work with multimedia and interactive elements, as predicted by e-textbook authors. Students are aware of the problem and choose appropriate computer equipment for the duration of learning from the emanual. The ability to re-open multimedia elements multiple times and the re-usability of passively and actively interactive elements is usually highly appreciated while the necessity to ensure appropriate technical conditions does not raise objections.

E-textbook authors analyse, usually with the help of IT departments, what format to choose for the publication and how it will be read. There are several standards for writing an e-textbook and binding multimedia and interactive elements to it. The HTML-based ones are gaining popularity due to the ease of reading of their contents in web browsers and the ease of inclusion in the courses published in the resources of LCMS portals, also available through browsers.

The ePUB format, based on the HTML standard, allows the e-textbook to be saved as a single file and is appropriate for e-textbooks intended to be copied to local student computers. Moreover, the CALIBER application, available free of charge, optimised to reading on tablets, laptops and desktops, is a very convenient solution. CALIBER enables reading, playing multimedia, and access to servers on the network. It should be sufficient for e-textbooks dedicated to students. 
Editing Tools. E-book (including e-textbook) readers are specialized devices used for displaying texts in electronic form or special applications installed on computers, laptops, smartphones, or tablets (Danowski, 2017). The latest e-readers make it possible to read e-books in several different e-book formats (Danowski, 2017). The variety of formats necessitated standardization. ePUB (electronic publication) is a standard file format for ebooks. Its latest version, i.e. the HTML5-based ePUB3, is currently the most popular format of e-books (Garrish, 2011). E-readers provide a convenient navigation system using hypertext. They allow, e.g., modifying the size, type and colour of fonts, and creating bookmarks. Some programs also have the possibility to edit text, with a built-in editor. Such programs are divided into creators and editors (processors). The former enables creating e-books from previously prepared HTML-files, text files, or multimedia files. Processors support the editing and formatting of e-books, therefore the knowledge of HTML language is not required. eCub is a free, simple platform, which is an example of an e-book creator. Its extended version is Jutoh (JUTOH, 2018), which additionally enables editing of an e-book prepared from HTML, docx, odt, or txt files, or developing it completely from scratch. Figure 1 shows the Jutoh user interface.

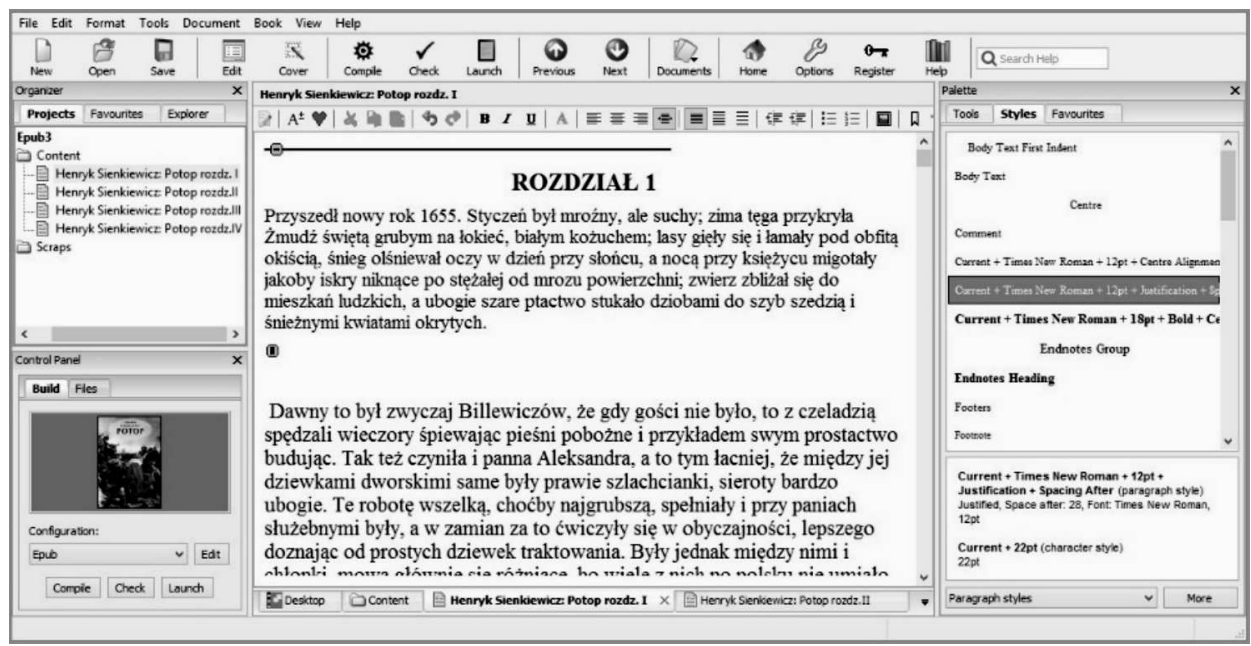

Figure 1. Jutoh user interface

The editor window is divided into four sections. It includes, e.g., the structure of the e-book, its cover, the styles used, and the content of the ebook being developed. It has different tools for text formatting, located in the top bar or in the Tools bar (Figure 2). 


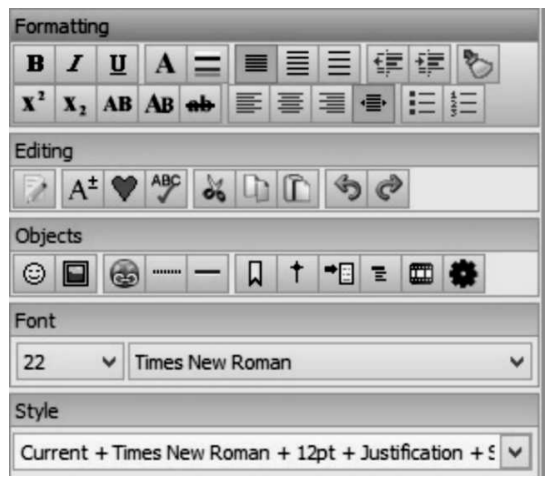

Figure 2. Editing tools in the Tools bar

There are a number of options in the Tools bar of the Formatting Palette, which enable text editing, e.g. bold, italicize, underline and strikethrough text, change indentation, justify, align it to the left or right, and add a bulleted or numbered list. Moreover, other options include spellcheck, copying, cutting and pasting items or text. Jutoh supports adding tag objects, i.e. it enables inserting special characters, graphic files, audio and video, links to other sites, bookmarks, comments, footnotes, tables, and text fields in the text.

More advanced capabilities of e-book creation and edition are available in ViewPorter (VIEWPORTER, 2018). Its edition toolkit is more developed, thus semantic attributes (Figure 3 ) can be specified, and every page edited in

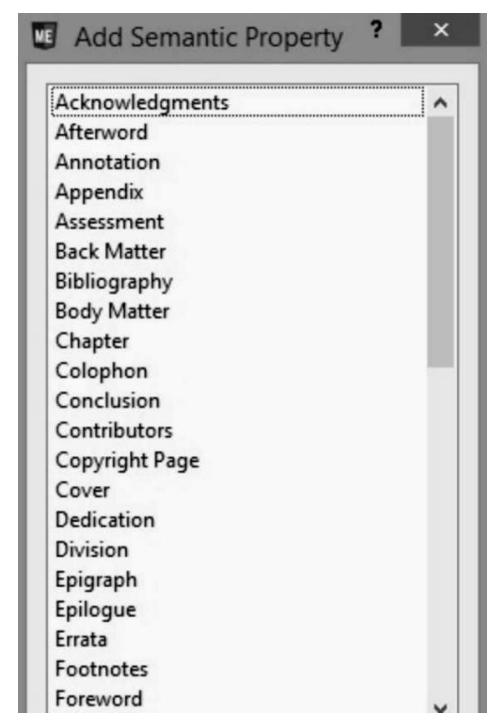

Figure 3. Window of semantic properties 
a different style. Examples of the semantics of pages are as follows: title page, introduction, bibliography, table of contents, annotation, index, copyright page, contributors, dedication, errata, landmarks, list of illustrations, list of audio/video clips, and revision history.

One of the most popular e-readers is Calibre (CALIBRE, 2018). The newest version of this program has the functionality of editing. By clicking on the Edytuj ksiazke icon (Figure 4), the Edit window opens (Figure 5).

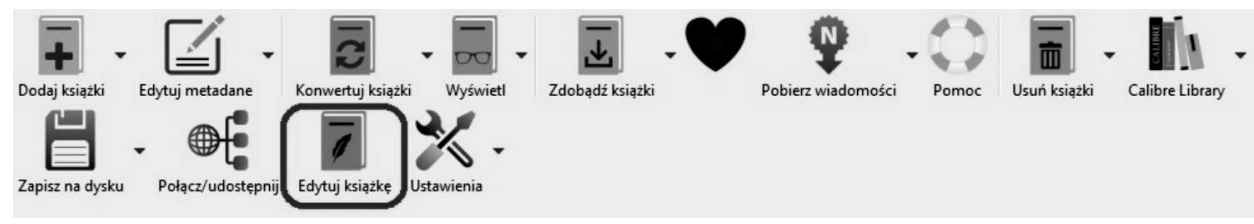

Figure 4. Calibre's Toolbar with Edytuj ksiażkę [Edit your book] selected

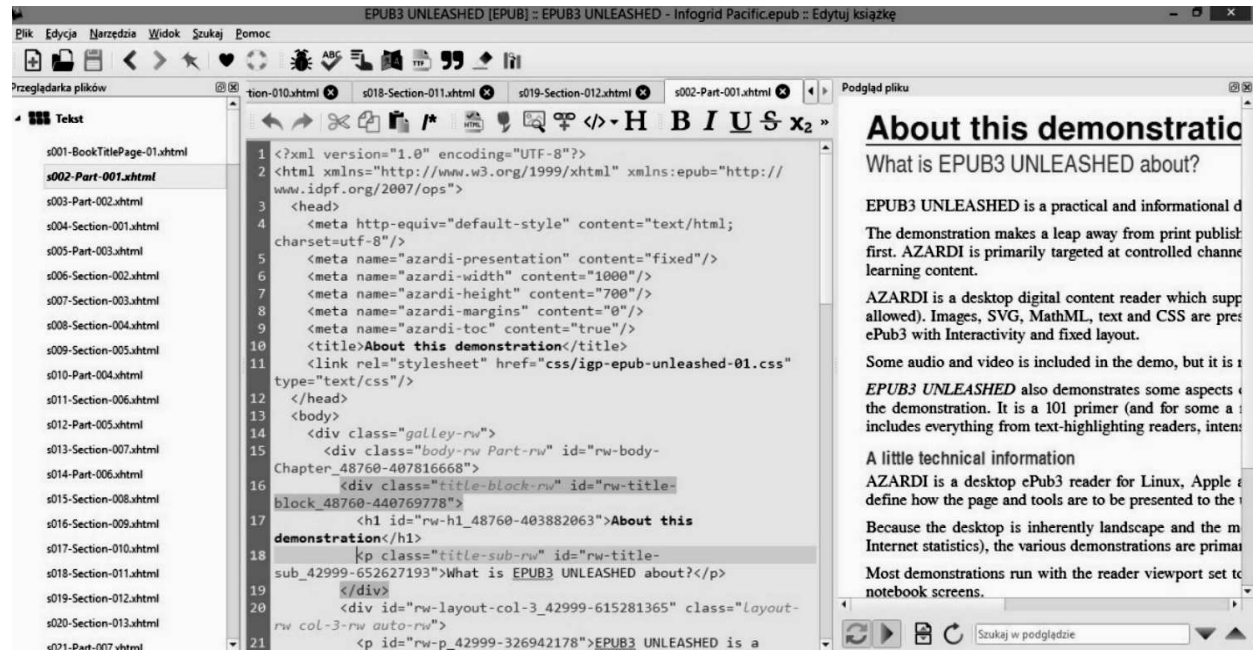

Figure 5. Calibre's edit window

Calibre's edit window is divided into three sections: in the first window there is a list of files the e-book consists of; in the second one there is the source of the selected file; and in the third one preview of the publication can be seen. The tools in the top bar enable content formatting. Calibre enables reading almost all the current formats of digital publications. It also has the capacity to convert one format into another.

Applications for creating e-books contain a built-in editor (processor), which enables the development of a new e-publication and modification of an already existing one. Together with e-readers they provide access to a variety of professional resources to empower both staff and students. 


\section{Expectations - Medical Students' Point of View}

The results of the research that targeted medical university students made it possible to specify their expectations regarding e-textbooks. The purpose of the research was to evaluate the process of creating an etextbook based on the opinions of its recipients and to verify the thesis that e-textbook implementation requires collaborative work of an interdisciplinary team (Blaž et al., 2012) consisting of:

- subject teachers (at a medical university they are mainly medical doctors);

- experts in the field of educational technologies (IT specialists responsible for technological implementation of the educational project; university IT department);

- online pedagogy specialists and educators specializing in the design of electronic materials, including e-textbooks for medical education.

This approach will make it possible to meet the expectations of recipients of this electronic form of knowledge transfer and support them in the process of education. A medical school is an example of a non-technical educational institution. Hence, the obtained results can be generalized from the study sample onto other universities with the same profile. Moreover, it is also an example of an educational institution whose graduates will expand and update their knowledge during the performance of highly specialized tasks. They are therefore prospective long-term users of e-textbooks and conscious developers of knowledge, constructing their own mental models in the course of lifelong learning.

Materials and Methods. The presented results are part of research in the field of e-learning and blended-learning in medical education, conducted in the academic year 2017-2018 at the Department of Emergency Medicine at the Poznan University of Medical Sciences (Faculty of Health Sciences). Out of 360 completed surveys, the 30 that contained valuable statements about the students' expectations regarding e-textbooks were selected. These were the answers to two open questions:

1. What are your expectations regarding an ideal / model medical etextbook?

2. What paper textbook do you value the most in your studies (justify why). What would you transfer from this paper handbook to an etextbook?

The study group $(\mathrm{n}=30)$ consisted of second-year full-time ( 8 people) and part-time (22 people) students who took part in emergency medicine classes. 
The presented results of the qualitative research constitute a pilot study in the field of medical university students' expectations regarding e-textbooks. In addition to the answers to the open questions, information obtained by teachers through direct interviews with the surveyed students were analyzed.

Results. The collected results are presented in Table 1. The first column contains information about the expectations of 30 students, grouped into fifteen categories. The order in which the categories are listed in the table is based on topic similarities in the students' opinions. In the second column, Type, the type of expectation is defined by assigning it either to the pedagogical category $(\mathrm{P})$ or the technological one $(\mathrm{T})$. Some expectations concern both areas so both types are specified in the table, the order indicating the advantage of one type over the other. The third column, Interpretation, a two-pole scale assessing the relevance of students' expectations is included, where $(+)$ shows that the expectation is considered relevant by the authors while $(-)$ indicates that it is irrelevant when it comes to either pedagogy- or technology-related issues regarding e-textbooks.

Table 1. Medical students' expectations regarding e-textbooks

\begin{tabular}{|c|c|c|c|}
\hline No. & Medical students' answers & $\begin{array}{c}\text { Type: } \\
\text { Technology }(\mathrm{T}), \\
\text { Pedagogy }(\mathrm{P})\end{array}$ & $\begin{array}{l}\text { Interpretation: } \\
\text { Relevant }(+) \text {, } \\
\text { Irrelevant }(-)\end{array}$ \\
\hline 1 & All topics should be included in an e-textbook & $\mathrm{P}$ & + \\
\hline 2 & Chronology of presented material is not needed & $\mathrm{P}, \mathrm{T}$ & - \\
\hline 3 & $\begin{array}{l}\text { Obligatory and additional material should be } \\
\text { marked accordingly }\end{array}$ & $\mathrm{P}$ & - \\
\hline 4 & $\begin{array}{l}\text { Short threads (parts of material) to study (time } \\
\text { to study one topic 15') }\end{array}$ & $\mathrm{P}, \mathrm{T}$ & + \\
\hline 5 & $\begin{array}{l}\text { Optimization of the e-textbook relatively to the } \\
\text { speed of mastery of the exam material }\end{array}$ & $\mathrm{T}, \mathrm{P}$ & + \\
\hline 6 & $\begin{array}{l}\text { E-textbook should be developed according to the } \\
\text { rule: the problem and a large number of details }\end{array}$ & $\mathrm{P}$ & - \\
\hline 7 & $\begin{array}{l}\text { Ratio of the amount of graphics and text to mul- } \\
\text { timedia elements } 20: 80\end{array}$ & $\mathrm{P}, \mathrm{T}$ & - \\
\hline 8 & $\begin{array}{l}\text { Preference towards animations and graphics in- } \\
\text { stead of text }\end{array}$ & $\mathrm{T}, \mathrm{P}$ & - \\
\hline 9 & A large number of examples, cases, case studies & $\mathrm{P}, \mathrm{T}$ & + \\
\hline
\end{tabular}




\begin{tabular}{|c|l|c|c|}
\hline No. & \multicolumn{1}{|c|}{ Medical students' answers } & $\begin{array}{c}\text { Type: } \\
\text { Technology (T), } \\
\text { Pedagogy (P) }\end{array}$ & $\begin{array}{c}\text { Interpretation: } \\
\text { Relevant (+), } \\
\text { Irrelevant (-) }\end{array}$ \\
\hline 10 & $\begin{array}{l}\text { Every way of using the e-textbook will be good. It } \\
\text { would be good if the e-textbook could be read as } \\
\text { a cookbook (selectively one specific topic) }\end{array}$ & $\mathrm{P}, \mathrm{T}$ & + \\
\hline 11 & $\begin{array}{l}\text { E-textbook should contain a guide only in justi- } \\
\text { fied cases }\end{array}$ & $\mathrm{P}, \mathrm{T}$ & + \\
\hline 12 & $\begin{array}{l}\text { Ability to print a chosen exercise from the e- } \\
\text { textbook and carry out some tasks in the paper } \\
\text { version }\end{array}$ & $\mathrm{P}$ & + \\
\hline 13 & Printable version & $\mathrm{P}, \mathrm{T}$ & - \\
\hline 14 & $\begin{array}{l}\text { Additional links to topics related to the subject } \\
\text { matter, but only those necessary }\end{array}$ & $\mathrm{P}, \mathrm{T}$ & + \\
\hline 15 & $\begin{array}{l}\text { E-textbook accessed primarily through a smart- } \\
\text { phone and iPad app }\end{array}$ & $\mathrm{T}$ & + \\
\hline
\end{tabular}

\section{Conclusions - Students' Expectations}

The research indicates the necessity of collaborative work of experts in the field of pedagogy and technology. Only their collaboration and cooperation within the two interlacing areas can guarantee successful development and implementation of quality e-textbooks. The best solution would be if teachers, content-delivering experts, had the basic competencies in both technology and pedagogy needed to build interactive online materials. Thus, it is necessary to train teaching staff responsible for the development of e-textbooks and make them aware in which areas they lack expertise. It is the task of the university, which in this way can support their employees and encourage them to become involved in the process of creating electronic materials and implementing IT innovations in education. As can be seen from the research, prospective users of medical etextbooks see the differences between traditional paper-based resources and innovative interactive online materials. The present technological advances can help meet their expectations regarding the creation and distribution of e-textbooks, which are required to be structured to facilitate effective learning. However, not all students' suggestions are relevant, which proves that they rarely use such educational materials and that universities and colleges do not support the process of education with innovative interactive online resources, i.e. e-textbooks. Building a successful structure and content requires the use of appropriate pedagogical approach tailored to 
the needs of medical education, which is a task for an experienced multidisciplinary team.

\section{Final Remarks}

According to the authors' research and the New Media Consortium's report, "The NMC Horizon Report: 2017 Library Edition" (Becker et al., 2017), the vast majority of countries starts creating e-textbooks from classic textbook in the file to print, later expanded and enriched in multimedia and other unprintable elements. The process of creating educational audio or video recordings is everywhere perceived as financially burdening to any project. At the same time, university libraries, rather than students themselves, are treated as those individuals purchasing and providing e-textbooks to students. A project to unify the formats of e-textbooks and resources and the authorization of electronic university rentals is being widely developed. An example to follow is the well-run project of educational academic resources at openstaxcollege.org. With huge funding and technological support, over 2,000 e-textbooks have been created. The editorial team is comprised of teams of dozens of authors, many of whom are specialists from prestigious universities around the world. Such activities are worth developing on a larger scale.

\section{R E F E R E N C E S}

Anderson, L. W., \& Krathwohl, D. R. (2001). A Taxonomy for Learning, Teaching, and Assessing: A Revision of Bloom's Taxonomy of Educational Objectives. New York: Longman.

Becker, S., Cummins, M., Davis, A., Freeman, A., Giesinger Hall, C., Ananthanarayanan, V., Langley, K., \& Wolfson, N. (2017). NMC Horizon Report: 2017 Library Edition. Austin, Texas: The New Media Consortium. Retrieved from https://www.learntechlib.org/p/177969/

Blaž, Z., Lipovec, A., Pesek, I., Zmazek, V., Šenveter, S., Regvat, J., \& Prnaver, K. (2012). What is an e-textbook? Metodički obzori, 7(2), 127-139.

Briggs, S. (2014). The Science of Attention: How To Capture And Hold The Attention of Easily Distracted Students. Retrieved from http://www.open colleges.edu.au/informed/features/30-tricks-for-capturing-students-attention /\#ixzz3BPhzBPxv

Burke, C. (2003). What is critical thinking? Retrieved from http://www.usc.edu/ schools/sppd/private/documents/doctoral/resources/critical_thinking.pdf

CALIBRE (2018). E-book manager. Retrieved from https://calibre-ebook.com 
Danowski, B. (2017). E-booki. Poradnik dla poczatkujacych e-czytelników. Poland: Helion.

Dutkiewicz, A., Kołodziejczak, B., Leszczyński, P., Mokwa-Tarnowska, I., Topol, P., Kupczyk, B., \& Siatkowski, I. (2018). Online Interactivity - A Shift Towards E-textbook-based Medical Education. Studies in Logic, Grammar and Rhetoric. Logical, Statistical and Computer Methods in Medicine, 56(69), $177-192$.

Garrish, M. (2011). What is EPUB 3? O'Reilly Media.

Heriot-Watt University. (1999). Lola: Learning About Open Learning, Training Manual. Glasgow: Heriot-Watt University.

Holme, R. (2009). Cognitive linguistics and language teaching. Basingstoke: Palgrave Macmillan.

Jump, L. (2011). Why university lecturers enhance their teaching through the use of technology: a systematic review. Learning, Media and Technology, 36(1), 55-68. doi: 10.1080/17439884.2010.521509

JUTOH (2018). E-book creator. Retrieved from http://www.jutoh.com/

Kirkwood, A., \& Price, L. (2014). Technology-enhanced learning and teaching in higher education: what is 'enhanced' and how do we know? A critical literature review. Learning, Media and Technology, 39(1), 6-36. doi: 10.1080/17439884.2013.770404

Kołodziejczak, B., Roszak, M., Kowalewski, W., Ren-Kurc, A., \& Bręborowicz, A. (2015). Participants academic distance education - case study. Technics, Technologies, Education, Management, 10(2), 242-249.

Lakoff, G. (1987). Women, Fire, and Dangerous Things: What Categories Reveal About The Mind. Chicago and London: The University of Chicago Press.

Mokwa-Tarnowska, I. (2013). Interaction and communication in the e-learning environment. In L. Zielińska \& W. Górski (Eds.), E-learning in Teaching Foreign Languages at the Tertiary Level (pp. 87-96). Kraków: Foundation of the Cracow University of Economics.

Mokwa-Tarnowska, I. (2017). E-Learning and Blended Learning in Academic Education: Teaching Aspects. Gdańsk, Poland: GUT Publishing House.

Ren-Kurc, A., Kołodziejczak, B., Roszak, M., \& Kowalewski, W. (2013). A new dimension of editorial competencies - ebook. In M. Dąbrowski \& M. Zając (Eds.), The role of e-education in the development of academic education (pp. 161-169). Warsaw: Foundation for the Promotion and Accreditation of Economic Education.

Roszak, M., \& Kołodziejczak, B. (2017). Teachers' skills and ICT competencies in blended learning. In E. Smyrnova-Trybulska (Ed.). Effective Development of Teachers' Skills in the Area of ICT and E-learning (pp. 91-103). KatowiceCieszyn, Poland: Studio-Noa.

Roszak, M., Mokwa-Tarnowska, I., \& Kołodziejczak, B. (2019). E-learning Competencies for University and College Staff. In E. Smyrnova-Trybulska, P. Kom- 
mers, N. Morze, \& J. Malach (Eds.). Universities in the Networked Society. Cultural Diversity and Digital Competences in Learning Communities (Critical Studies of Education: Vol. 10; pp. 205-224). Springer International Publishing. Retrieved from https://www.springer.com/gp/book/97830300 50252

Smith, J., M. (2013). Panel discussion at Media and Learning Conference, 2013, Brussels.

Szulc, J. (2018). Personalization in e-learning. An overview of solutions. The Scientific Papers of Faculty of Electrical and Control Engineering Gdansk University of Technology, 58, 81-84.

VIEWPORTER (2018). E-book creator. Retrieved from http://viewporter.com/

Walker, R., Voce, J., \& Ahmed, J. (2012). 2012 Survey of Technology Enhanced Learning for higher education in the UK. Oxford, UK: Universities and Colleges Information Systems Association. Retrieved from http://www.ucisa.ac. $\mathrm{uk} /$ /media/groups/ssg/surveys/TEL_survey_2012_with\%20Apps_final 